\title{
MEAN PLATELET VOLUME AS A PREDICTIVE BIOMARKER FOR RETINOPATHY IN PATIENTS WITH TYPE 2 DIABETES
}

\author{
Asma Tasneem, Samina Naeem, Nasir Ud Din, Helen Mary Robert, Maria Farid, M. Khizar Niazi \\ Combined Military Hospital Lahore/National University of Medical Sciences (NUMS) Pakistan
}

\begin{abstract}
Objective: To determine the association of mean platelet volume with diabetic retinopathy in our population.

Study Design: Cross sectional study.

Place and Duration of Study: Department of Hematology \& Ophthalmology, Combined Military Hospital Lahore, from Jul to Dec 2020.

Methodology: A total of 146 known patients with type 2 diabetes were enrolled in this study. They included 78 patients with diabetic retinopathy (group 1) and 68 without diabetic retinopathy (group 2). Five (5ml) of whole blood was extracted from patients through clean venipuncture in a tube containing EDTA and mean platelet volume was generated through automated haematological analyzer Sysmex KX-21 and HbA1c was generated through automated analyzer Cobas c501.

Result: A total of 146 patients with type 2 diabetes were included in this study. The age of patients ranged from 25-70 years (Mean age: $53.3 \pm 0.02$ years). Out of 146 patients $66(45.2 \%)$ were males and $80(54.8 \%)$ were females. Among patients with type 2 diabetes $78(53.4 \%)$ has retinopathy while $68(46.6 \%)$ have no retinopathy. A statistically significant difference $(p<0.005)$ was observed in mean platelet volume and platelet distribution width among patients with retinopathy to those without retinopathy.

Conclusion: Mean platelet volume plays a significant role in the determination of retinopathy with type 2 diabetes and helps to monitor progression of disease.
\end{abstract}

Keywords: Diabetic retinopathy, Mean platelet volume, Platelet distribution width.

\footnotetext{
This is an Open Access article distributed under the terms of the Creative Commons Attribution License ( https://creativecommons.org/licenses/by-nc/4.0/), which permits unrestricted use, distribution, and reproduction in any medium, provided the original work is properly cited.
}

\section{INTRODUCTION}

Diabetes mellitus (DM) is a leading cause of macro- and microvascular complications ${ }^{1}$. Visual impairment in diabetes mellitus is known as diabetic retinopathy and its underlying pathological mechanism is microangiopathy. Patients with diabetes mellitus are at a high risk to develop diabetic retinopathy which is the most important and common complication with an escalating rate of morbidity ${ }^{2}$. Proliferative diabetic retinopathy is an advanced stage of retinal neovascularization that can lead to complications such as retinal detachment, hemorrhage, and glaucoma ${ }^{3}$. Retinopathy in patients with type $2 \mathrm{DM}$ has an association with a few genetic and environmental factors. The onset and severity of retinal neovascularization significantly differs among individuals with type $2 \mathrm{DM}$, due to strong association of diabetic microangiopathy with certain risk and protective factors ${ }^{4}$. Multiple factors associated with the development of diabetic retinopathy (DR) include genetic factors, duration of diabetes, obesity, dyslipidemia, smoking, hypertension, and hyperglycemia refractive index. Impaired insulin action in patients with diabetes may enhance platelet activation resulting

Correspondence: Dr Asma Tasneem, Resident Haematology, Combined Military Hospital, Lahore Pakistan

Received: 26 Feb 2021; revised received: 20 May 2021; accepted: 24 May 2021 in microvascular (retinopathy) complications ${ }^{5}$.

Platelets play a key role in the maintenance of homeostasis and the function of platelets is correlates with mean platelet volume (MPV) ${ }^{6}$. MPV is used as a marker to indicate the platelet's average size and activity ${ }^{7}$. The larger platelets exhibit a more dense granular structure with increased production of thromboxane A2 and resulting in plateletcollagen induced aggregation and hyper-responsiveness to $\mathrm{ADP}^{8}$. Structural and functional changes in platelets have been reported in DM possibly due to pathological process. Noticeable increase in MPV has been identified in patients with $\mathrm{DM}^{9}$. The large platelets are haemostatically more competent and are a reason for vascular thrombosis. They can lead to myocardial infarction, retinopathy and cardiovascular disease.

Retinopathy is one of the most important complications of diabetes mellitus. Increased MPV is associated with increased risk of vascular complications. The identification of large sized platelets can be done through a routine hematological parameter MPV. The aim was to assess possible association of mean platelet volume with diabetic retinopathy in our population.

\section{METHODOLOGY}

It was a cross sectional validation study, carried out in the department of Haematology in liason with 
department of Ophthalmology after taking approval from ethical review board CMH (IRB \# 190/2020) Combined Military Hospital Lahore, Pakistan, from July to December 2020.

A sample size of 146 was calculated using frequency of MPV in patients with type 2 diabetes with WHO sample size calculator considering 5\% level of significance, and 95\% confidence interval. Sampling technique used was non-probability consecutive sampling ${ }^{10}$. All adult patients who were diagnosed cases of diabetes as per American Diabetic Association (ADA) irrespective of their gender, socio-economic status, duration of the disease and age above 25 years were included in this study. Patients were divided into two groups based on the presence or absence of retinopathy of any grade diagnosed on fundoscopy. Group I included 50 patients having retinopathy of any grade and group II (control group) had 50 patients without retinopathy. Patients with sepsis (WBC $\left.>11 \times 10^{9}\right)$, anemia $(\mathrm{Hb}<10 \mathrm{~g} / \mathrm{dl})$, Thrombocytopenia $\left(<150 \times 10^{9} / 1\right)$ and those taking antiplatelet drugs were excluded. Five $(5 \mathrm{ml})$ blood was extracted from patients through a clean venipuncture in a tube containing EDTA. Hematological parameters including mean platelet volume and platelet count were measured for all patients using automated hematological analyzer Sysmex KX21 and $\mathrm{HbA1C}$ was generated through automated analyzer Cobas c501. Diabetic retinopathy was diagnosed by ophthalmoscopic examination by experts.

Data was analysed using SPSS version 23. Mean and SD were calculated for numerical variables and percentage and frequency for categorical variables. Mean platelet volume (MPV) between group I and group II was compared, considering ( $p$-value $\leq 0.05)$ to be statistically significant. Independent sample t-test was applied to determine $95 \%$ confidence interval and significant difference between two groups.

\section{RESULTS}

A total of 146 patients were included in this study who met the inclusion criteria. The age of patients ranged from 25-70 years (Mean age: $53.3 \pm 0.02$ years) among those $28(19.2 \%)$ were $<40$ years and 118 were ranged $40-70$ years. Out of 146 patients $66(45.2 \%)$ were males and $80(54.8 \%)$ were females. Among patients with type 2 diabetes 78 (53.4\%) has retinopathy while $68(46.6 \%)$ have no retinopathy (figure).

Table showed the comparison of platelet indices in patients with diabetes having retinopathy to those without retinopathy. A statistically significant difference ( $p$-value $<0.005)$ was observed in mean platelet volume (MPV) among patients with retinopathy to those without while platelet count and platelet distribution width (PDW) has no statistically significant difference ( $p$-value >0.05) among both groups.

Mean platelet count were $229.6 \pm 39.1$ in group A and $215.0 \pm 32.5$ in group B. Mean platelet volume were $10.3 \pm 1.56$ and $7.7 \pm 1.01$ in patient with retinopathy and without retinopathy respectively. Mean platelet width in group A and B were $9.4 \pm 1.4$ and $9.1 \pm$ 1.17 respectively.

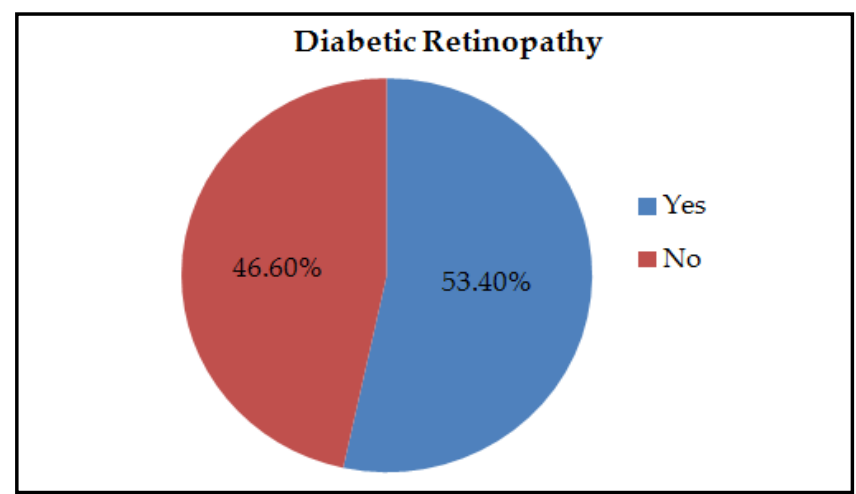

Figure: Percentage of diabetic retinopathy among study population. Among patients with type 2 diabetes 78 (53.4\%) has retinopathy while $68(46.6 \%)$ have no retinopathy.

Table: Comparison of platelet indices in patients with diabetes having retinopathy to those without retinopathy.

\begin{tabular}{l|c|c|c}
\hline \multirow{2}{*}{ Parameters } & \multicolumn{2}{|c|}{ Study Groups } & \multirow{2}{p-}{} \\
\cline { 2 - 3 } & $\begin{array}{c}\text { Group A } \\
(\mathbf{n = 7 8 )}\end{array}$ & $\begin{array}{c}\text { Group B } \\
\text { (n=68) }\end{array}$ & value \\
\hline $\begin{array}{l}\text { Platelet count } \\
\left(\times 10^{9} / \mathrm{L}\right)\end{array}$ & $229.6 \pm 39.1$ & $\begin{array}{c}215.0 \pm \\
32.5\end{array}$ & 0.081 \\
\hline $\begin{array}{l}\text { Mean platelet } \\
\text { volume (fL) }\end{array}$ & $10.3 \pm 1.56$ & $7.7 \pm 1.01$ & 0.005 \\
\hline $\begin{array}{l}\text { Platelet distribution } \\
\text { width (fL) }\end{array}$ & $9.4 \pm 1.4$ & $9.1 \pm 1.17$ & 0.006 \\
\hline
\end{tabular}

\section{DISCUSSION}

$\mathrm{DM}$ is one of the most common medical problems in our community, having significant mortality and morbidity. Main clinical feature of this disease is hyperglycemia (raised blood glucose level) due to a defect in insulin secretion or an increase resistance to insulin at cellular level. It is divided into two subtypes. Type 1 or the insulin dependent diabetes mellitus and type 2 the non-insulin dependent diabetes mellitus. Type 2 diabetes is the most common form accounting for around $90-95 \%$ of all the diabetic cases worldwide. Patients with diabetes mellitus have an increased risk of developing micro- and macro vascular complications. Retinopathy is one of the most important complications of diabetes mellitus. Mean platelet volume 
(MPV) is used as a marker to indicate the size and platelet activity. Increased MPV is associated with increased risk of vascular complications. Large platelets are haemostatically more competent and associated with high thrombotic potential hence place the patient at a higher risk status.

$\mathrm{DM}$ is considered a common cause of vascular complications (micro and macro-vascular) which leads to multi organ disease mainly neuropathy, nephropathy, retinopathy and stroke ${ }^{11}$. The definition of diabetic retinopathy according to American Academy of Ophthalmology is damage to blood vessels in the retina. These blood vessels can swell and leak and sometimes abnormal new blood vessels grow on the retina. There are two main stages of diabetic eye disease. NPDR (non-proliferative diabetic retinopathy) is the early stage of diabetic eye disease. In NPDR, tiny blood vessels leak, making the retina swell. PDR (proliferative diabetic retinopathy) is the advanced stage. It happens when the retina starts growing new blood vessels. This is called neovascularization. These fragile new vessels often bleed into the vitreous. If bleed is significant, it might block vision. Proliferative diabetic retinopathy is very serious, and can steal both central and peripheral (side) vision.

A large group of population with type $2 \mathrm{DM}$ experiences micro and macro-vascular complications to an unavoidable extent. So, modifications in risk factor are required to prevent incessant complications. People with inadequate glycemic control, hypertension and obesity, have a higher prevalence of microvascular complications in diabetics ${ }^{12}$. Many studies have demonstrated that high MPV leads to an encounter with conditions such as metabolic syndrome, stroke, and diabetes mellitus. Patients with DM are at greater risk for coronary artery disease and cerebrovascular events than the normal person ${ }^{13}$. A series of studies have shown that increased platelets function or elevated MPV has a strong association with DM.

In patient with diabetes the platelets activation occurs due to high level of prothrombotic components like thromboxane A2, thromboxane B2, platelet factor 4 , serotonin, and platelet-derived growth factor ${ }^{14}$. Mean platelet volume is used as a marker to indicate the size, platelets activity and storage of giant or young platelets that increases the secretion of serotonin and $\beta$-thromboglobulin which ultimately enhance the production of thromboxane A2 and increased susceptibility of aggregation. Papanas et al, reported the association of elevation of thromboxane A2, reduction of pros- tacyclin level and high MPV with microvascular complications in patients with diabetic retinopathy as compared to normal persons ${ }^{11}$.

In our study, we determined association of MPV with diabetic retinopathy. MPV was higher in patients with diabetic retinopathy as compared to control group. Buch A and colleagues determined an association between high MPV values and retinopathy indicating increasing activity of the platelets and high incidence of proliferative retinopathy ${ }^{15}$. Walinjkar et al, have also reported that mean platelet volume exhibits a strong and independent relationship with diabetes. They reported substantial relation in cardiovascular complications in diabetes mellitus ${ }^{16}$. Ito $\mathrm{T}$ and colleagues have described that taurine (an amino acid present in greater amount in platelets) has an essential role to maintain the cell volume through osmoregulation. Its concentration decreases in diabetic condition. The oral administration of taurine overcomes the platelet aggregation to bring back to a normal state. A reduction in taurine level is associated with increased mean platelet volume in diabetic retinopathy ${ }^{17}$.

After the onset of DM $>60 \%$ of the patients develop diabetic retinopathy and blindness over the years. The initial characterization of diabetic retinopathy start with less severe non-proliferative to more severe proliferative retinopathy with vascular occlusions, hemorrhages, cotton wool spots, and increased tendency to form neovascularization ${ }^{18}$. Muhiddin et al, reported that in all stages of retinopathy in comparison to the control group mean platelet volume was significantly high $^{19}$. Van der Meijden et al, have described the strong induction of neovascularization is due to vascular endothelial growth factor which is produced by hypoxic condition. The hypoxia in diabetic retinopathy stimulates neovascularization as a repercussion of occlusions and micro-aneurysms ${ }^{20}$. The growth factors which induce proliferative retinopathy through neovascularization are epidermal growth factor, insulin growth factor- 1 and platelet-derived growth factors ${ }^{21}$. Yamashiro et al, reported substantially elevated levels of mean platelet volume, specifically in case of proliferative retinopathy where activated platelets liberate growth factors having more contribution in progress to develop complicated disease ${ }^{22}$. The significantly increased levels of MPV in pro-liferative retinopathy suggest that growth factors relea-sed from activated platelets indirectly contribute to disease progression.

This study revealed a positive correlation of the severity of retinopathy with MPV. As the MPV increa- 
ses the degree of retinopathy increases from nonproliferative to proliferative and leads to symptoms such as blurred vision or even blindness. A study conducted by Gimeno-orna et al, identified that a few cases of the proliferative retinopathy were linked with coronary arteries disorders ${ }^{23}$. Tuzcu et al, explained the pathophysiology of MPV as a significant marker raised in vascular disease ${ }^{24}$.

Despite the strong association of MPV with diabetic retinopathy found in the present study, it has some limitations including its relatively small sample size. The difference in MPV between patients with and without retinopathy was close to the significance level. This difference might be found statistically significant in a larger sample size. Useful information about the relationship between MPV and diabetic microvascular complications can be found if findings are augmented with similar studies with large sample size including people from various areas and ethnicities.

\section{CONCLUSION}

MPV values were significantly higher in patients with DR as compared to control group. High MPV correlated with severity of DR. In particular, MPV values were statistically significantly higher in patients who developed proliferative DR compared with patients without retinopathy. MPV can be used as an indicator that provides easy access to functional properties and platelet volume parameters. So, it will be very easy in monitoring the severity and progression of the disease.

\section{CONFLICT OF INTEREST}

This study has no conflict of interest to be declared by any author.

\section{REFERENCES}

1. Powers AC, Kasper DL, Fauci AS, Kasper DL, Hauser SL, Jameson JL, et al. Diabetes mellitus In: Harrison's Principles of Internal Medicine, 20e. eds. Harrison's Principles of Internal Medicine. New York Mc Graw Hill 2012: 1(1): 2968-3.

2. Gupta P, Gan AT, Man RE, Fenwick EK, Kumari N, Tan G, et al. American Academy of Ophthalmology. Impact of incidence and progression of diabetic retinopathy on vision-specific functioning. Ophthalmol 2018; 125(9): 1401-9.

3. Shah CA. Diabetic retinopathy: A comprehensive review. Ind J Med Sci 2008; 62(12): 500-19.

4. Yau JW, Rogers SL, Kawasaki R, Lamoureux EL, Kowalski JW, Bek T, et al. Global prevalence and major risk factors of diabetic retinopathy. Diabet Care 2012; 35(3): 556-64.

5. Yilmaz T, Yilmaz A. Relationship between altered platelet morphological parameters and retinopathy in patients with type 2 diabetes mellitus. J Ophthalmol 2016; 2016(2): 1-5.

6. Shah B, Sha D, Xie D, Mohler ER, Berger JS. The relationship between diabetes, metabolic syndrome, and platelet activity as measured by mean platelet volume: the National Health And Nutrition Examination Survey, 1999-2004. Diabet Care 2012; 35(5): 1074-78.

7. Yuri Gasparyan A, Ayvazyan L, P Mikhailidis D, D Kitas G. Mean platelet volume: a link between thrombosis and inflammation?. Curr Pharm Des 2011; 17(1): 47-58.

8. Vongchan P. Platelet morphology and structural profile of platelet plasma membrane. J Associat Med Sci 2009; 42(3): 221-21.

9. Hekimsoy Z, Payzin B, Örnek T. Mean platelet vol-ume in type 2 diabetic patients. J Diabetes Complicat 2004; 18(3): 173-6.

10. Güngör AA, Gürsoy G, Güngör F, Bayram SM, Atalay E. The relationship of mean platelet volume with retinopathy in type 2 diabetes mellitus. Turk J Med Sci 2016; 46(5): 1292-9.

11. Papanas N, Symeonidis G, Maltezos E, Mavridis G, Karavageli E, Vosnakidis TH, et al. Mean platelet volume in patients with type 2 diabetes mellitus. Platelets 2004; 15(8): 475-8.

12. Agrawal A, Kumar S, Bhagwati J. Correlation of Platelet Indices with Clinical Profile in Elderly Patients: A Study in Rural Teaching Hospital. Ann Med Health Sci Res 2018; 8(3): 163-69.

13. Kutlucan A, Bulur S, Kr S, Bulur S, Önder E, Aslantas Y, et al. The relationship between mean platelet volume with metabolic syndrome in obese individuals. Blood Coagul Fibrinolysis 2012; 23(5): 388-90.

14. Kim JH, Bae HY, Kim SY. Response: clinical marker of platelet hyperreactivity in diabetes mellitus. Diabetes Metab J 2013; 38(2): 423-8.

15. Buch A, Kaur S, Nair R, Jain A. Platelet volume indices as predictive biomarkers for diabetic complications in type 2 diabetic patients. J Lab Physicians 2017; 9(2): 84-88.

16. Walinjkar RS, Khadse S, Kumar S, Bawankule S, Acharya S. Platelet indices as a predictor of microvascular complications in type 2 diabetes. Indian J Endocrinol Metab 2019; 23(2): 206-10.

17. Ito T, Schaffer SW, Azuma J. The potential usefulness of taurine on diabetes mellitus and its complications. Amino Acids 2012; 42(5): 1529-9.

18. Ateş O, Kiki I, Bilen H, Keleş M, Kocer I, Kulaçoğlu DN, et al. Association of mean platelet volume with the degree of retinopathy in patients with diabetes mellitus. Eur J Gen Med 2009; 6(2): 99-2.

19. Muhiddin HS, Kamaruddin MI, Andi Muhammad Ichsan B. Vitreous and serum concentrations of vascular endothelial growth factor and platelet-derived growth factor in proliferative diabetic retinopathy. Clin Ophthalmol 2020; 14(1): 1547-52.

20. van der Meijden PE, Ozaki Y, Ruf W, De Laat B, Mutch N, Diamond S. Theme 1: Pathogenesis of venous thromboembolism (and post-thrombotic syndrome). Thromb Res 2015; 136(1): S3-S7.

21. Citirik M, Beyazyildiz E, Simsek M, Beyazyildiz O, Haznedaroglu IC. MPV may reflect subcinical platelet activation in diabetic patients with and without diabetic retinopathy. Eye (Lond) 2015; 29(3): 376-9.

22. Yamashiro K, Tsujikawa A, Ishida S, Usui T, Kaji Y, Honda Y, et al. Platelets accumulate in the diabetic retinal vasculature following endothelial death and suppress blood-retinal barrier breakdown. Am J Pathol 2003; 163(1): 253-9.

23. Gimeno-Orna JA, Faure-Nogueras E, Castro-Alonso FJ, BonedJuliani B. Ability of retinopathy to predict cardiovascular disease in patients with type 2 diabetes mellitus. Am J Cardiol 2009; 103 (10): 1364-7.

24. Tuzcu EA, Arıca S, Ilhan N, Daglioglu M, Coskun M, Ilhan O, et al. Relationship between mean platelet volume and retinopathy in patients with type 2 diabetes mellitus. Graefes Arch Clin Exp Ophthalmol 2014; 252(2): 237-40. 